\title{
Research on Simulation and Control Strategy of Doubly - fed Wind Power Generation System
}

\author{
Hong $\mathrm{Ai}^{1, a, *}$, Jin Bai ${ }^{1, b}$ \\ ${ }^{1}$ Institute of Problem Solving, Harbin University of Science and Technology, No.52 Xuefu Road, \\ Harbin, China \\ aihong@hrbust.edu.cn, ${ }^{b}$ 690048856@qq.com \\ *Hong Ai
}

Keywords: Double-fed Induction Generator, Control Strategy, Power decoupling strategy.

\begin{abstract}
The new energy research and development of the development and utilization of wind power system is the focus and hot spots of the world. DFIG (Double-fed Induction Generator) has become the main object of wind power research with its unique operating characteristics. Decoupling Control of Active Power and Reactive Power of Doubly-Fed Machines is a Key Issue in the Research and Development of Wind Power Generation Technology. In this paper, the dual-PWM converter controlled variable speed constant frequency power generation system, the use of wind energy under different wind speeds, combined with the maximum wind energy tracking, to improve the traditional controller performance ${ }^{[1]}$. The stator flux-oriented DFIG generation vector control strategy with adaptive proportional resonance (PR) is proposed. The power decoupling regulation is realized by controlling the frequency, phase and amplitude of rotor current. The modeling and simulations of the DFIG power generation operation control system are carried out by Matlab. The results verify the correctness and effectiveness of the strategy and control method.
\end{abstract}

\section{Introduction}

With the progress of science and technology, the global energy consumption continues to grow high, environmental pollution is serious, the global energy is facing a crisis. To develop a kind of clean, renewable energy sources to replace the conventional energy has a very important significance. The decoupling control of active power and reactive power of DFIG is the key issue in the research and the development of wind power generation technology ${ }^{[2]}$. Vector control technology is the core of active and reactive decoupling. By using the unified theory of motor and coordinate transformation, it can be equivalent to a DC motor, torque component and excitation components, in order to achieve decoupling control. Vector control system the vector control system usually needs to be vector oriented in the axis coordinate system, and through a series of calculations to become a mathematical model. By studying the mathematical model of the doubly- 
fed machine, the vector equation in the stationary coordinate system can be obtained, vector control is carried out, and the operation relationship between current, active power and reactive power in the rotating coordinate system can also be obtained ${ }^{[3]}$. Although the vector control system structure is complex, but the implementation is relatively easy for double-fed motor control strategy.

\section{PR Control Strategy for Power Generation Operation}

PI control stator flux direction control system to achieve the power decoupling control, but the motor internal parameters affected by the temperature rise, if not, the coupling compensation is difficult to achieve stable operation ${ }^{[4]}$. PR control stator flux oriented control system for AC signal without static error adjustment. And complete in the $\alpha-\beta$ coordinates, eliminating the need for complex, cumbersome coordinate transformation process, no compensation items, reduce the internal requirements of the parameters, and better improve the stability of the system.

\subsection{An Adaptive PR Control System}

In the doubly fed VSCF, the wind speed is constantly changing, but in order to maintain the variable-speed constant-frequency state we need to transform the frequency of AC excitation is the so-called slip frequency $\omega_{\mathrm{s}}$. PR control system in the $\alpha-\beta$ coordinate of the AC signal without static difference adjustment, the resonant frequency $\omega_{0}=\omega_{\mathrm{s}}$, to achieve the AC excitation adaptive adjustment process $^{[4]}$. The control of system structure shown in Figure 1.

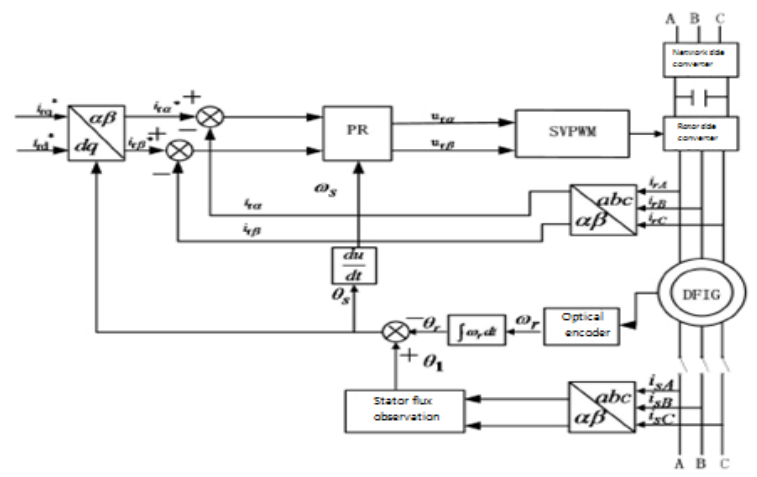

Figure 1 PR under the control of the rotor converter decoupling control diagram.

\subsection{System Simulation and Result Analysis}

In order to verify that the power decoupling control of the doubly-fed machine is controlled by PR.The initial reactive power of the system is 0 , the wind speed of the wind turbine is $7.6 \mathrm{~m} / \mathrm{s}$ and the system runs in $0.5 \mathrm{~s}$.

\subsubsection{Active Power Regulation}

The wind speed of the wind turbine is changed to $5.6 \mathrm{~m} / \mathrm{s}$ at $0.8 \mathrm{~s}$. The changes of voltage and current waveform, active power, reactive power, stator current and rotor current are observed on the stator side of the system, which shown in Figure 2. 


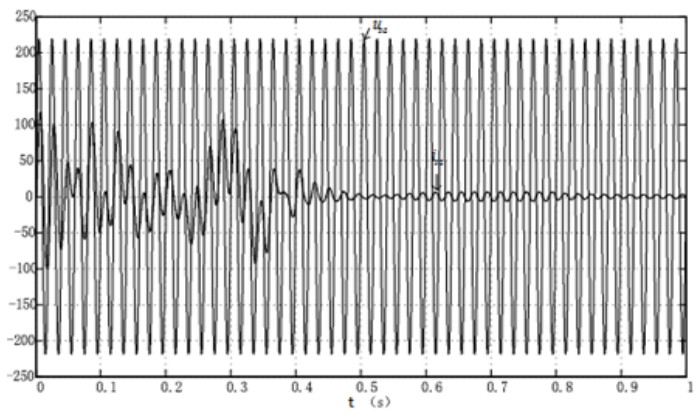

Figure 2 Stator voltage and current waveform.

As shown in Figure 2, The sinusoidal curve of the stator side current is inverted after the grid connection for $0.5 \mathrm{~s}$ and the stator side voltage, which indicates that the doubly-fed machine operates in the power state with uniform power factor. At $0.8 \mathrm{~s}$, the wind speed changes and the stator current decreases obviously, and the active power changes obviously.
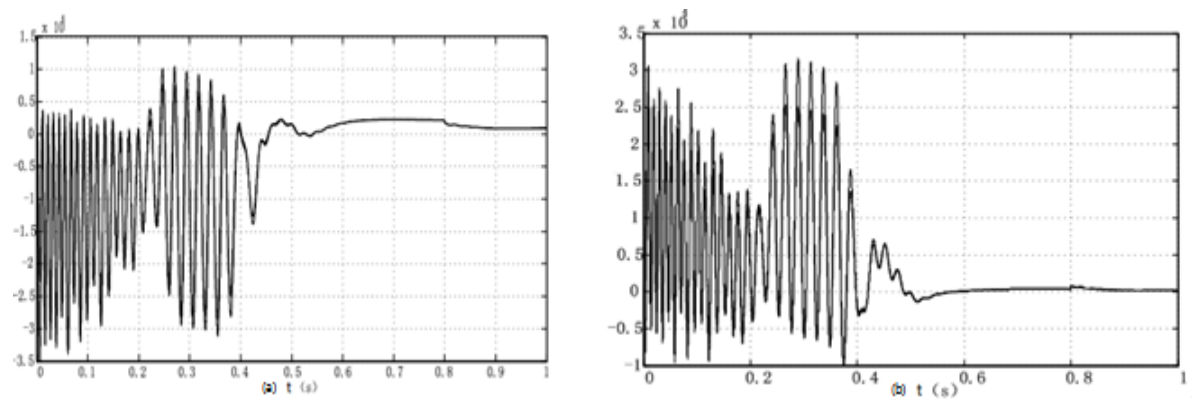

Figure 3 Given active(a) $\backslash$ reactive(b) power and active power waveform.

Figure 3(a) shows the comparison between active power and actual active power. The given active power is calculated by the rotor current. The actual power follows the given active power perfectly. When the wind speed is changed, the active power changes obviously. Figure 3 (b) shows a comparison of the given reactive power and active power. It can be found that the initial value of reactive power is 0 , active power changes in $0.8 \mathrm{~s}$, the reactive power small fluctuations, and soon stabilized, and restore the value to the initial state, which proves a good power performance.
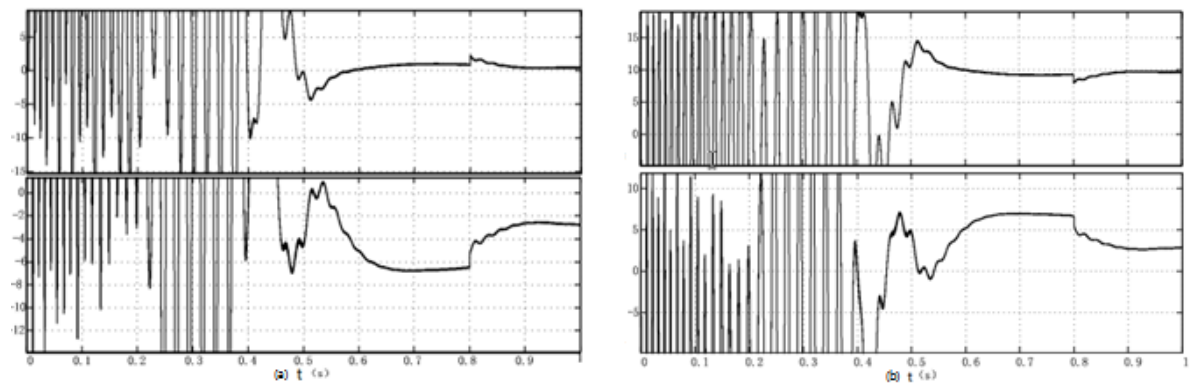

Figure 4 d-q component of stator(a) $\backslash$ rotor(b) current.

The active power of the system changes at $0.8 \mathrm{~s}$, the d-q-axis component changes of the stator current and rotor current are shown in Figure 4(a) and Figure 4(b). It is found that the q-axis component of the stator and rotor changes after $0.8 \mathrm{~s}$, while the d-axis component of the stator and rotor has a short fluctuation after $0.8 \mathrm{~s}$, and the initial value is recovered very quickly. It is proved that the q-axis component of the stator flux vector. The active power is controlled in the system. 


\subsubsection{Reactive power regulation}

The reactive power of the system changes from 0 to 1000 at $0.8 \mathrm{~s}$. Observe the change of voltage and current waveform, active power, reactive power, stator current and rotor current. To Figure 5.

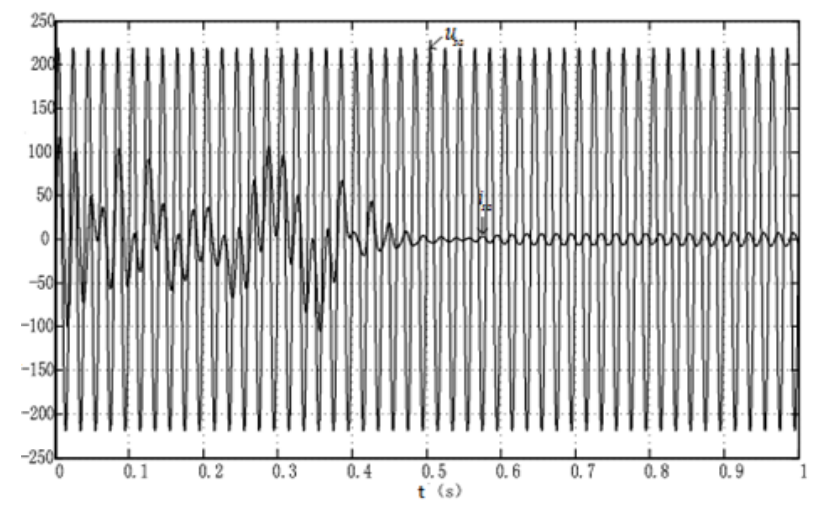

Figure 5 Stator voltage and current waveform.

As shown in Figure 5, the stator current waveform remains sinusoidal after grid-connected for $0.5 \mathrm{~s}$ and is in reverse phase with the stator-side grid voltage. This shows that the doubly-fed machine operates in the power state with unity power factor of 1 . The reactive power changes at $0.8 \mathrm{~s}$ and the stator current phase changes obviously.
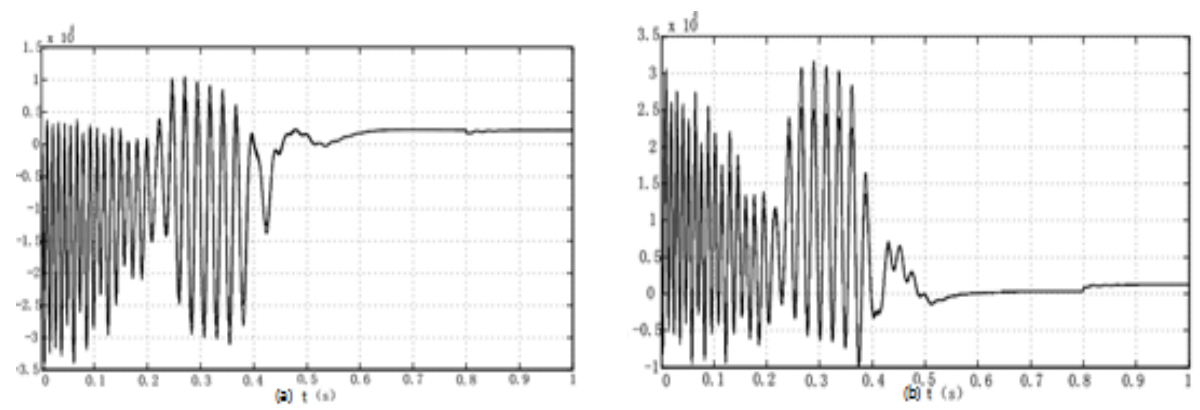

Figure 6 Given active power and active(a) $\backslash$ reactive(b) power waveform.

Figure 6 (a) shows a comparison of the given active power and the actual active power, a given active power is calculated by the rotor current. The actual power follows the given active power perfectly. When the reactive power is changed at $0.8 \mathrm{~s}$, the active power fluctuates slightly and soon stabilizes, and the value returns to the initial state. Figure 6(b) shows the comparison of the reactive power and the actual reactive power. It can be found that the initial reactive power is 0 and the reactive power is perfectly following the given reactive power when the reactive power changes in $0.8 \mathrm{~s}$, which proved that the power running performance is good.
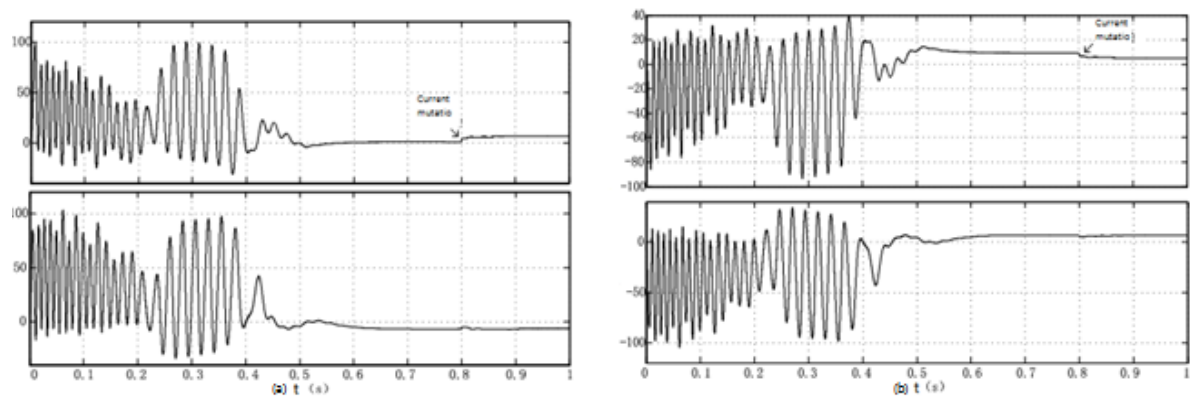

Figure 7 d-q component of stator(a) $\backslash$ rotor(b) current. 
The reactive power of the system changes at $0.8 \mathrm{~s}$, and the d-q-axis component of stator current and rotor current changes are shown in Figure 7(a) and Figure 7(b). It is found that the d-axis component of the stator and rotor changes after $0.8 \mathrm{~s}$ and the q-axis component of the stator and rotor fluctuates briefly after 0.8 . The $\mathrm{d}$-axis component of the rotor is instantaneously restored to the initial value, and it is proved that the d-axis component of the flow controls the reactive power in the stator flux directional vector control system.

\section{Conclusions}

This paper discusses the model ideas and implementation methods of the DFIG wind power generation system simulation model based on Matlab / Simulink. Based on P and Q decoupling DFIG stator magnetic field orientation control strategy for in-depth analysis. Combined with the maximum wind energy tracking and specific control strategy. The validity of the strategy and control method are verified by simulation ${ }^{[5]}$.

\section{Acknowledgements}

*This work is supported by Ministry of Education Humanities and Social Sciences engineering science and technology talents special (15JDGC020).

\section{References}

[1] MENG Yan-feng,DONG Zhi-ran,HU Shu-ju,et al. (2012)Research on an improved control strategy for harmonics restraint of DFIG system. Applied Mechanics and Materials.

[2] Wang L,Xie X R,Jiang Q R,et al. IEEE Transactions on Power Systems. (2015)Investigation of SSR in practical DFIG-based wind farms connected to a series-compensated power system.

[3] Adams J,Carter C,Huang S H. Transmission and Distribution Conference and Exposition (T\&D). (2012)ERCOT experience with sub-synchronous control interaction and proposed remediation.

[4] Ganti, Vijay Chand,Singh, Bhim,Aggarwal, Shiv Kumar,Kandpal, Tara Chandra. IEEE Transactions on Sustainable Energy. (2012)DFIG-based wind power conversion with grid power leveling for reduced gusts.

[5] Ying Wang,Kunlun Zhang,Mi Zhou. Journal of Modern Transportation. 2012 (2)Suppression of thrust fluctuation of doubly-fed linear motor[J] . 